\title{
Myeloid transformation of plasma cell myeloma: molecular evidence of clonal evolution revealed by next generation sequencing
}

\author{
Jonathon H. Gralewski ${ }^{1}$, Ginell R. Post ${ }^{1}$, Frits van Rhee $^{2}$ and Youzhong Yuan ${ }^{1 *}$ (ID
}

\begin{abstract}
Background: Plasma cell myeloma (PCM) is a neoplasm of terminally differentiated B lymphocytes with molecular heterogeneity. Although therapy-related myeloid neoplasms are common in plasma cell myeloma patients after chemotherapy, transdifferentiation of plasma cell myeloma into myeloid neoplasms has not been reported in literature. Here we report a very rare case of myeloid neoplasm transformed from plasma cell myeloma.

Case presentation: A 60-year-old man with a history of plasma cell myeloma with IGH-MAF gene rearrangement and RAS/RAF mutations developed multiple soft tissue lesions one year following melphalan-based chemotherapy and autologous stem cell transplant. Morphological and immunohistochemical characterization of the extramedullary disease demonstrated that the tumor cells were derived from the monocyte-macrophage lineage. Next generation sequencing (NGS) studies detected similar clonal aberrations in the diagnostic plasma cell population and post-therapy neoplastic cells, including IGH-MAF rearrangement, multiple genetic mutations in RAS signaling pathway proteins, and loss of tumor suppressor genes. Molecular genetic analysis also revealed unique genomic alterations in the transformed tumor cells, including gain of NF1 and loss of TRAF3.

Conclusion: To our knowledge, this is the first case of myeloid sarcoma transdifferentiated from plasma cell neoplasm. Our findings in this unique case suggest clonal evolution of plasma cell myeloma to myeloma neoplasm and the potential roles of abnormal RAS/RAF signaling pathway in lineage switch or transdifferentiation.
\end{abstract}

Keywords: Clonal evolution, Myeloid sarcoma, Molecular profiling, Next generation sequencing, Transdifferentiation, Plasma cell myeloma, RAS/RAF signaling pathway

\section{Background}

Plasma cell myeloma (PCM) is a neoplasm of terminally differentiated B lymphocytes and most often involves the bone marrow. Malignant plasma cells are defined immunophenotypically by diminished or increased expression of at least two antigens not present on non-neoplastic plasma cells. For example, malignant plasma cells show decreased or loss of CD45 and/or CD19 expression and may aberrantly express CD56, CD117, and/or CD20 [1]. Immunohistochemical stains performed on diagnostic

\footnotetext{
* Correspondence: yyuan@uams.edu

'Department of Pathology, University of Arkansas for Medical Sciences, Little Rock, AR 72205-7199, USA

Full list of author information is available at the end of the article
}

biopsies demonstrate retained expression of nonneoplastic plasma cell antigens (e.g. CD138 and MUM1) and cytoplasmic light chain restriction. PCM is characterized by molecular heterogeneity, including balanced translocations involving the immunoglobulin heavy chain locus, complex karyotypes, and mutations in the RAS signaling cascade [2-4]. For example, KRAS, NRAS and BRAF mutations are detected in approximately $33 \%$ of newly diagnosed PCM patients $[3,4]$.

Disease progression in PCM can be associated with disease at extramedullary sites, high grade plasma cell morphology, acquisition of additional genetic mutations or possibly reactivation of Epstein Barr virus infection [3, 5-7]. Although plasma cells may resemble blasts and 
express aberrant myeloid antigens [5, 8], malignant plasma cells retain expression of a subset of plasma cell markers and demonstrate light chain restriction, allowing immunohistochemical classification of the tumor as PCM. A subset of patients with PCM develop secondary malignancies following high dose chemotherapy. Therapy-related myeloid neoplasms are the most common secondary malignancy in PCM [9]. We recently described the rapid onset of therapy-related acute leukemia in patients in complete remission for PCM. In this series, the immunophenotype and karyotype of the leukemic cells was distinctly different than that seen in the original PCM [10].

Here we report a rare case of multiple soft tissue sarcomas arising in a patient in complete remission for high-risk PCM. Immunohistochemical stains and flow cytometry showed that the tumor cells expressed monocyte-macrophage (CD163, CD68 and lysozyme) and myeloid antigens (myeloperoxidase and CD13) without plasma cell markers. Fluorescence in situ hybridization (FISH) and next generation sequencing (NGS) studies demonstrated a clonal relationship between the diagnostic PCM and transformed tumor cells, including loss of tumor suppressor genes and multiple, clonal/subclonal mutations in the RAS pathway. To our knowledge, this is the first reported case of myeloid transformation in PCM.

\section{Case presentation}

A sixty-year-old Caucasian male presented to our institution with chest pain. A complete blood count showed anemia (hemoglobin of $8.0 \mathrm{~g} / \mathrm{dL}$; reference range 13-17 $\mathrm{g} / \mathrm{dL}$ ) and thrombocytopenia (platelet count of $69,000 / \mu \mathrm{L}$; reference range $150,000-450,000 /$ $\mu \mathrm{L})$. Review of the peripheral blood smear revealed $12 \%$ circulating plasma cells. Additional laboratory evaluation demonstrated an elevated total serum protein of $11.3 \mathrm{~g} / \mathrm{dL}$ (reference range: $6.4-8.3 \mathrm{~g} / \mathrm{dL}$ ) and serum M-component $(6.8 \mathrm{~g} / \mathrm{dL})$ with increased IgG $(9010 \mathrm{mg} /$ $\mathrm{dL}$; reference range: $700-1600 \mathrm{mg} / \mathrm{dL}$ ) and free lambda light chain $(120 \mathrm{mg} / \mathrm{dL}$; reference range $0.57-2.63 \mathrm{mg} /$ $\mathrm{dL})$. The diagnostic bone marrow biopsy demonstrated a hypercellular bone marrow for age extensively involved by lambda light chain-restricted plasma cells (Fig. 1). Concurrent flow cytometric analysis showed that the neoplastic plasma cells were positive for CD38, CD138, and CD20 (heterogeneous) and negative for CD45, CD27, CD81, CD56, and CD19. Cytogenetic analysis of the bone marrow aspirate cells revealed a complex karyotype: 43,XY,del(1)(p13p32),+ 3,der(3;6)(q10;p10),del (5)(q15q33),? $\quad \mathrm{t}(9 ; 15)(\mathrm{p} 24 ; \mathrm{q} 24),-10, \operatorname{add}(13)(\mathrm{p} 11.2), \operatorname{del}(14)$ (q24),-20,-22,inc[3]/46,XY[17]. Myeloma FISH studies were uninformative due to paucity of analyzable plasma cells. Gene array studies were consistent with high-risk cMAF subgroup [2]. Foundation $\mathrm{One}^{\mathrm{Tm}}$ NGS studies

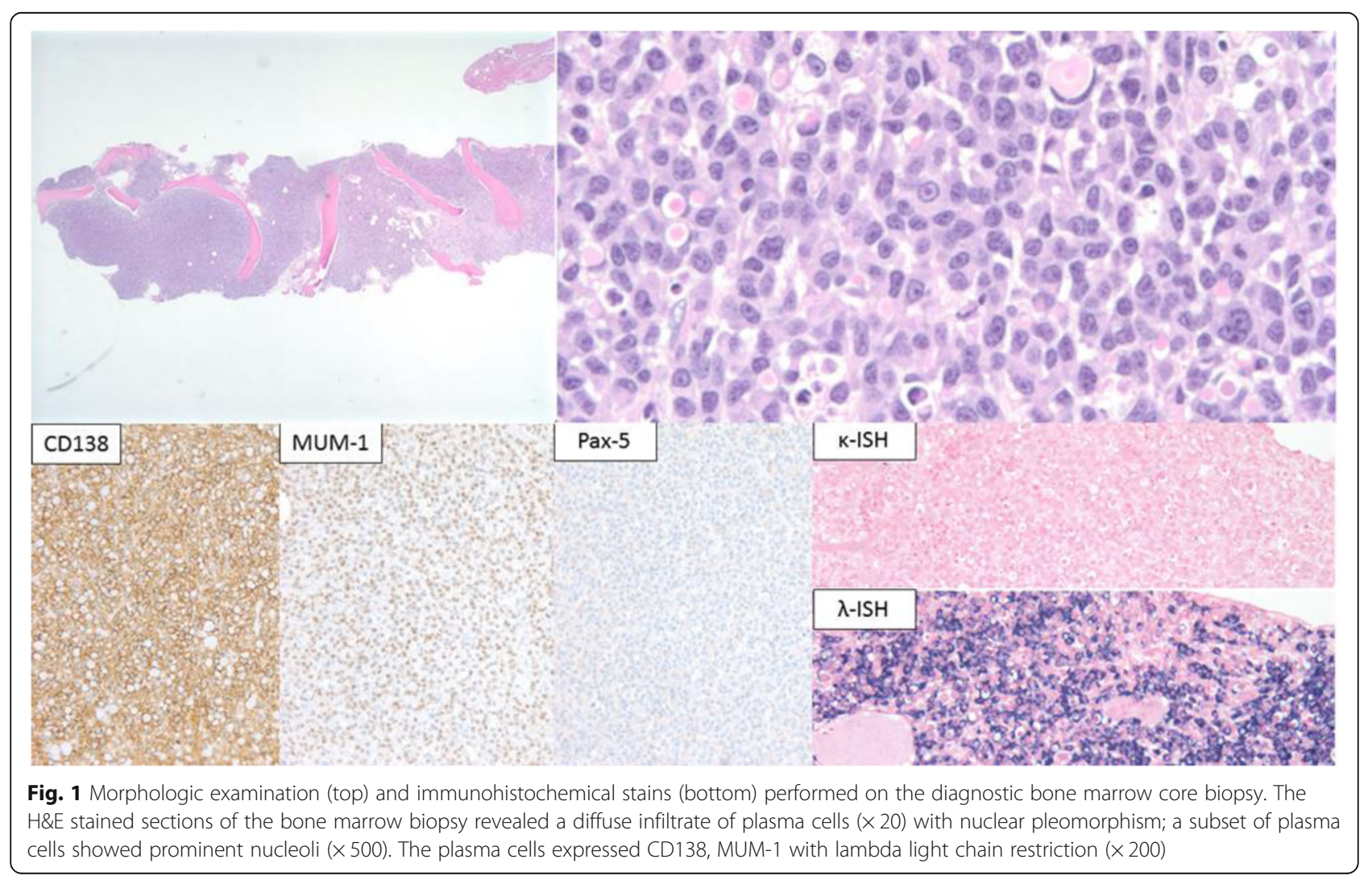


revealed IGH-MAF gene rearrangement and several genomic alterations, including BRAF G469V and G466A, KRAS A146V, MAP3K6 Q943, CDKN2A/B loss, TRAF3 R505 and PTPRO E379K (Table 1). Magnetic-resonance imaging (MRI) and positron-emitted topography (PET) scans highlighted multiple focal lesions in the cervical spine, rib cage, tibia, and fibula, but no extramedullary disease.

The patient received induction chemotherapy (Velcade, Dexamethasone, Thalidomide-Cisplatin, Doxorubicin, Cyclophosphamide and Etoposide; VDTPACE) followed by cytoreduction (Cytoxan, Etoposide, Mesna, Cisplatin, Dexamethasone and Cytarabine; PACMED) and bridging therapy with carfilzomib and daratumumab. An autologous stem cell transplant was performed 10 months after initial diagnosis. Two months after stem cell transplant, bone marrow evaluation was morphologically negative for PCM with no minimal residual disease detected by 8-color flow cytometry; however, PET-CT imaging showed multiple focal lesions in the bilateral femoral shafts, humeri and a $1.8 \times 1.2 \mathrm{~cm}$ mass in the right perineal region (Fig. 2). A PET-CT imaging study showed that the lesion in the perineal region had increased in size to approximately $3.1 \times 2.1 \mathrm{~cm}$ with new extramedullary lesions noted in the left mandibular soft tissue, lungs/mediastinal lymph nodes and liver (Fig. 2). The differential diagnosis included multifocal myelomatous disease progression versus infectious etiology. The patient underwent fine needle aspiration of mediastinal lymph nodes and punch biopsy of the gingival lesion.

The Diff-Quik ${ }^{\mathrm{Tn}}$ stained sections prepared from the mediastinal lymph node FNA showed large atypical cells with abundant cytoplasm with immature chromatin (Fig. 3). The H\&E stained sections prepared from the cell block demonstrated similar morphologic features including an infiltrate of immature monocytic cells with rare mature granulocytes (Fig. 3). Immunohistochemical stains showed that the neoplastic cells expressed myeloperoxidase (MPO; subset), CD163, lysozyme, and were

Table 1 Next-generation sequencing of the diagnostic bone marrow aspirate and left gingival lesion

\begin{tabular}{ll}
\hline Bone marrow aspirate & Soft tissue \\
\hline BRAF1 G466A subclonal, & BRAF G469A \\
G469 subclonal & KRAS A146V \\
KRAS A146V & IGH IGH-MAF rearrangement \\
IGH IGH-MAF rearrangement & CDKN2A/B loss \\
CDKN2A/B loss & MAP3K6 Q943, truncation exon 22 \\
MAP3K6 Q943, truncation & \\
EXon 22 & NF1 R2450 \\
TRAF3 R505 & CCT6B splice site 615-2A > G TNFAIP3 W85 \\
PTPRO E379K - subclonal &
\end{tabular}

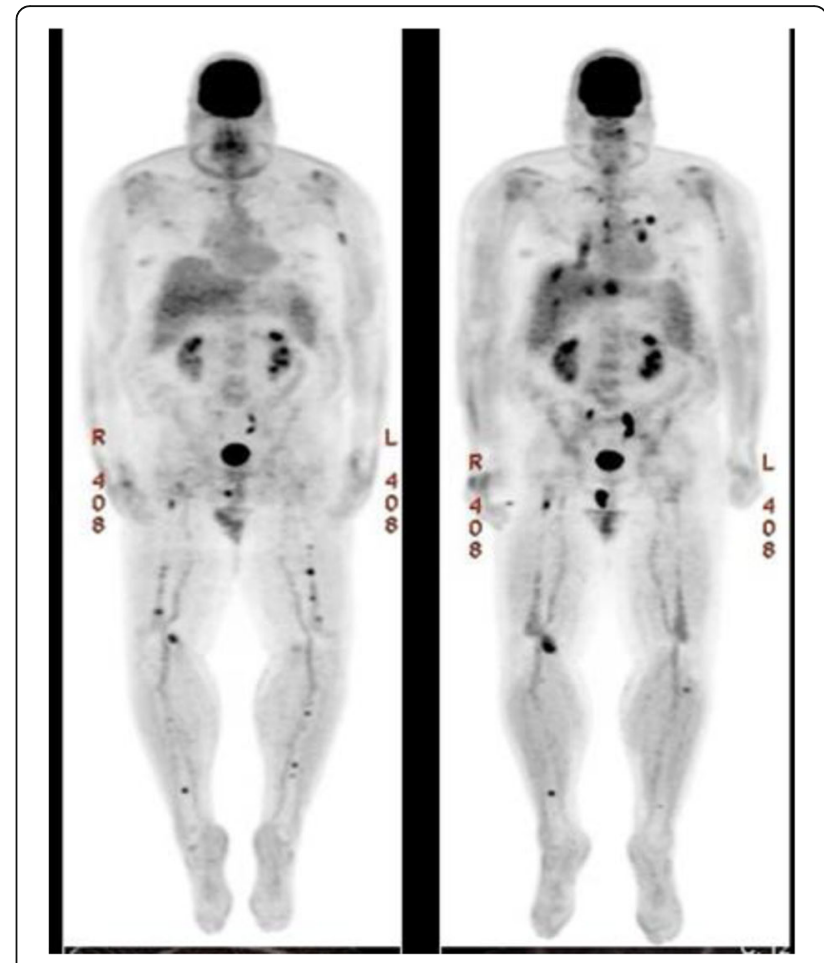

Fig. 2 PET-CT image (left) showing the lesions in the proximal right tibia, right proximal femur and perineum. PET-CT image (right) demonstrate increased size of the previous lesions and new lesions in the left mandibular soft tissue, liver, lungs and mediastinum three months after first time PET-CT

negative for CD138 (Fig. 3). Additional immunohistochemical studies revealed positivity for CD68 and lack of MUM-1, PAX-5, CD56, S-100, and P53 expression (not shown). Concurrent flow cytometric analysis revealed atypical cell populations with distinct CD45 expression and forward and side scatter properties comprising $80 \%$ of total analyzed events. One population with increased side and forward scatter comprised $40 \%$ of total events. These cells expressed CD45 (bright), CD33, HLA-DR, CD14 (bright), CD11b (bright) and CD36 (variable) (Fig. 4; red), consistent with monocytic lineage. A second population of cells with decreased forward and side scatter showed a similar immunophenotype with variable expression of CD33 and dimmer expression of CD45, $\mathrm{CD} 11 \mathrm{~b}$ and CD14 (Fig. 4; blue). Both populations were negative for CD34 and CD117. The H\&E stained sections of the gingival biopsy showed similar morphologic features, including a dermal infiltrate of large, immature cells with irregular nuclear contours and ample cytoplasm (not shown). Immunohistochemical stains of the gingival biopsy showed an immunophenotype similar to the mediastinal lymph node, including CD68, CD163, lysozyme, MPO (subset) expression and lack of CD138, MUM-1, PAX-5, CD34, and CD56 expression (not shown). FISH studies performed on the mediastinal 


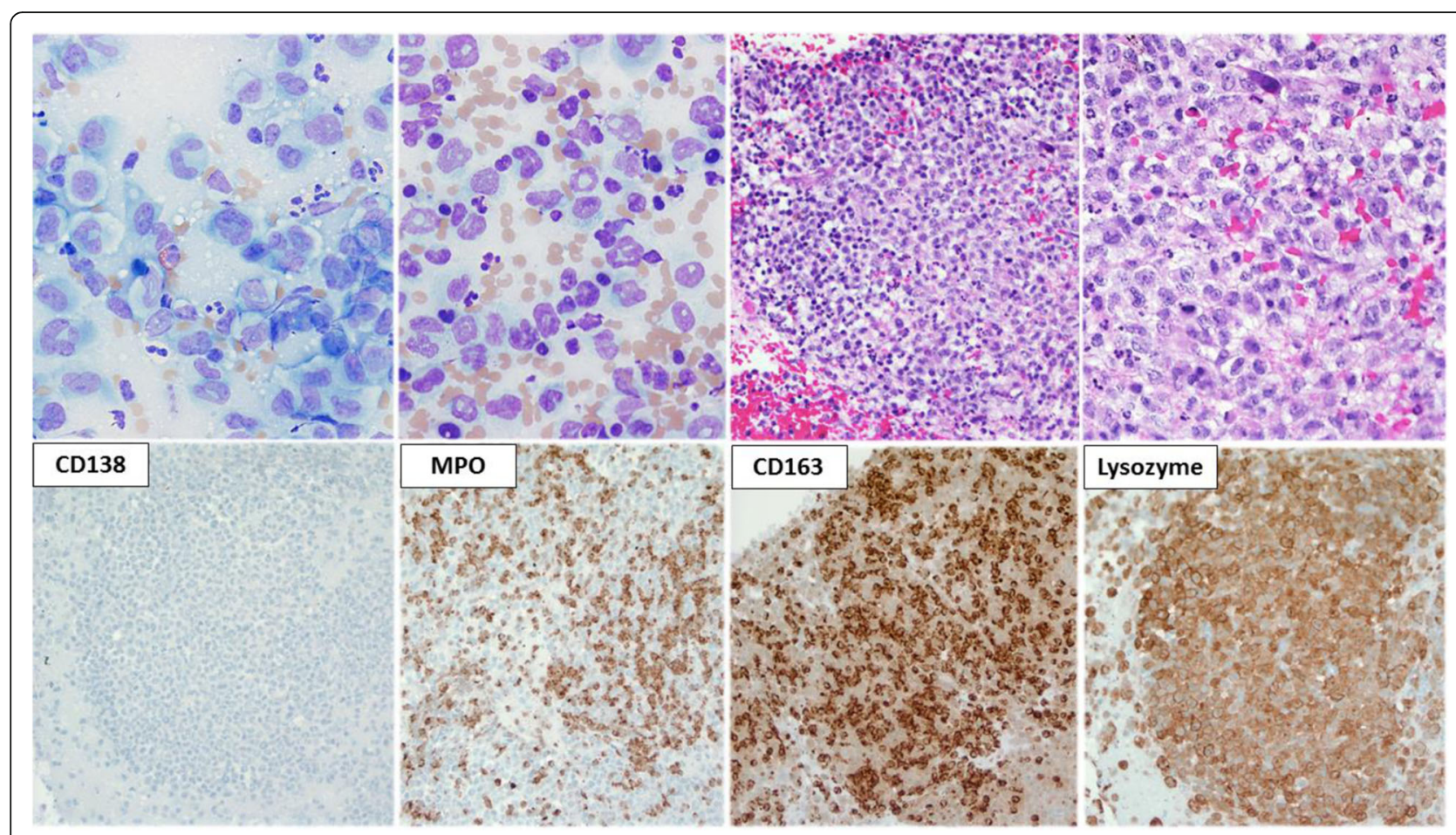

Fig. 3 Morphologic examination and immunohistochemical stains performed on the fine needle aspirate of the mediastinal lymph node. The Diff-Quik ${ }^{\text {TM }}$ stained slides show large monocytoid cells with ample blue-grey cytoplasm, round to irregular nuclear contours and immature chromatin ( $\times 500$, top-left). The H\&E stained sections prepared from the cell block shows a diffuse infiltrate of monocytoid cells with ample cytoplasm and round to irregular nuclear contours ( $\times 200$ and $\times 400$, top-right). The tumor cells were negative for CD138 and positive for myeloperoxidase (MPO), CD163 and lysozyme $(\times 200)$
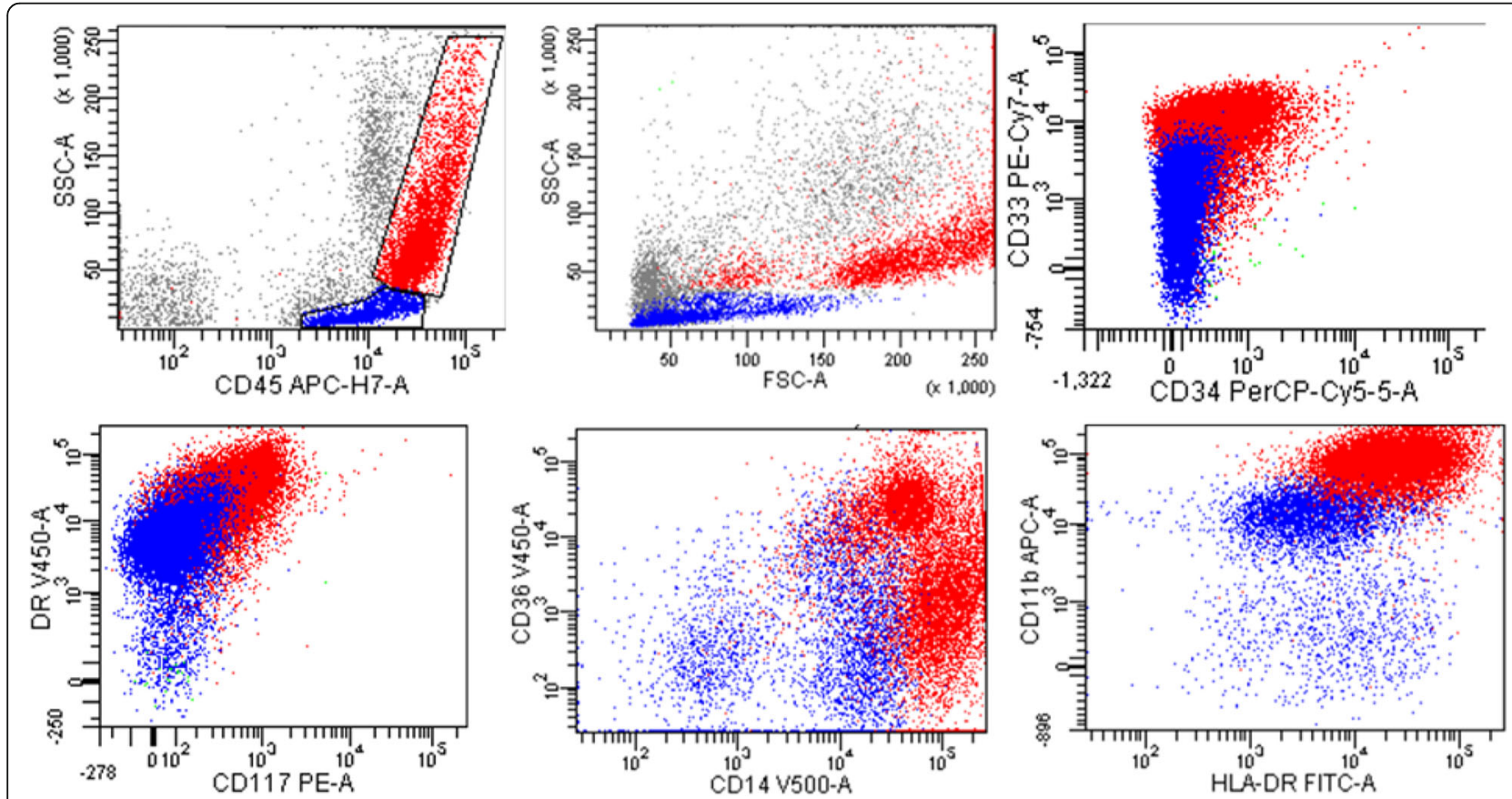

Fig. 4 Flow cytometric analysis of mediastinal lymph node revealed two cell populations with distinct forward and side scatter and CD45 expression intensity. One population with increased side and forward scatter comprised $40 \%$ of total events (red). This population expressed CD33, HLA-DR, CD36 (variable), CD14 (bright) and CD11b (bright) and were negative for CD34 and CD117. A second population of cells with decreased forward and side scatter showed a similar immunophenotype with variable expression of CD33 and dimmer CD11b and CD14 (blue). These cells were also negative for CD34 and CD117 
lymph node and gingival biopsies revealed a translocation between chromosomes 14 and 16 [IGH and MAF genes; $\mathrm{t}(14 ; 16)(\mathrm{q} 32 ; \mathrm{q} 23)]$ in approximately $76 \%$ and $73 \%$ of interphase nuclei examined (Fig. 5), respectively. FISH probes for $\mathrm{t}(11 \mathrm{q} 23)$ and $\operatorname{del}(17 \mathrm{p} 13.1)$ showed normal signal patterns. Cytogenetic studies performed on the mediastinal lymph node were unsuccessful due to no cell growth. The gingival lesion showed a normal karyotype $(46, \mathrm{XY}[4] / 45, \mathrm{Y},-\mathrm{X}[1])$ with a low mitotic index. NGS studies performed on the gingival lesion demonstrated IGH-MAF rearrangement, BRAF and KRAS mutations, CDKN2A/B loss, TNFAIP3 and NF1 mutations (Table 1).

The patient received induction chemotherapy $(7+3$ regimen of cytarabine and idarubicin). At follow up, the patient developed neutropenic fever with persistent pancytopenia despite receiving recombinant granulocytic colony stimulating factor. He was re-admitted one week later for possible sepsis/bacteremia. As the patient's health continued to deteriorate and the soft tissue masses continued to grow, he decided to stop treatments and medical interventions. The patient went into palliative care approximately two months after the diagnosis of multifocal myeloid sarcoma and died shortly thereafter.

\section{Discussion}

We report a case of multiple soft tissue sarcomas in a patient in complete remission for high-risk PCM. The neoplastic cells at the extramedullary sites were large with immature chromatin and expressed the monocytemacrophage antigen CD163 [11], CD14 and CD68 as well as myeloid antigens $\mathrm{MPO}$ and CD13. The tumor cells were negative for S-100 and CD138, consistent with absence of dendritic cell differentiation [12, 13] or relapsed PCM, respectively. The immature nuclear features and expression of the myeloid antigens MPO and CD13 was most consistent with the diagnosis of myeloid sarcoma with monocytic differentiation. Furthermore, FISH studies showed IGH-MAF translocation in the transformed cells and PCR identified an IGH gene rearrangement. NGS- based assays revealed similar genomic alterations suggesting a clonal relationship between the original PCM and secondary myeloid sarcoma.

Hematopoiesis, once viewed as a unidirectional maturation of pluripotent hematopoietic stem cells into specific lineages (such as lymphoid and myeloid), shows considerable plasticity in both normal and malignant hematopoietic cells. Lineage switching has been described in histiocytic sarcoma (HS), Langerhans cell sarcoma or dendritic cell tumor that occur secondary to or synchronous with mediastinal germ cell tumors [14], lymphoid [12, 13, 15-22], and myeloid malignancies [23, 24]. Histiocytic sarcoma cells are derived from bone marrow monocyte precursors [25], expresses monocyte-macrophage antigens (CD163, CD68, and lysozyme) and lack expression of myeloid antigens such as CD33, CD13 and MPO [11, 25, 26]. The identification of clonal associations between HS and antecedent malignancies suggests that HS or myeloid sarcoma can differentiate from other cell lineages or develop from a common progenitor cell [12-20, 23, 27].

Several studies indicate that commitment to specific lineage and lineage conversion depends on the activity of lineage-specific transcription factors [28-30]. For example, PAX-5 is required for $\mathrm{B}$ cell differentiation and commitment to B cell lineage [31-33]. B cells that lack PAX-5 expression can differentiate into macrophages, dendritic cells, osteoclasts, granulocytes and natural killer cells [32]. Similarly, the activity of the transcription factors PU.1 and CCAAT/enhancer binding protein alpha $(\mathrm{C} / \mathrm{EBP} \alpha)$ are important for myeloid progenitor

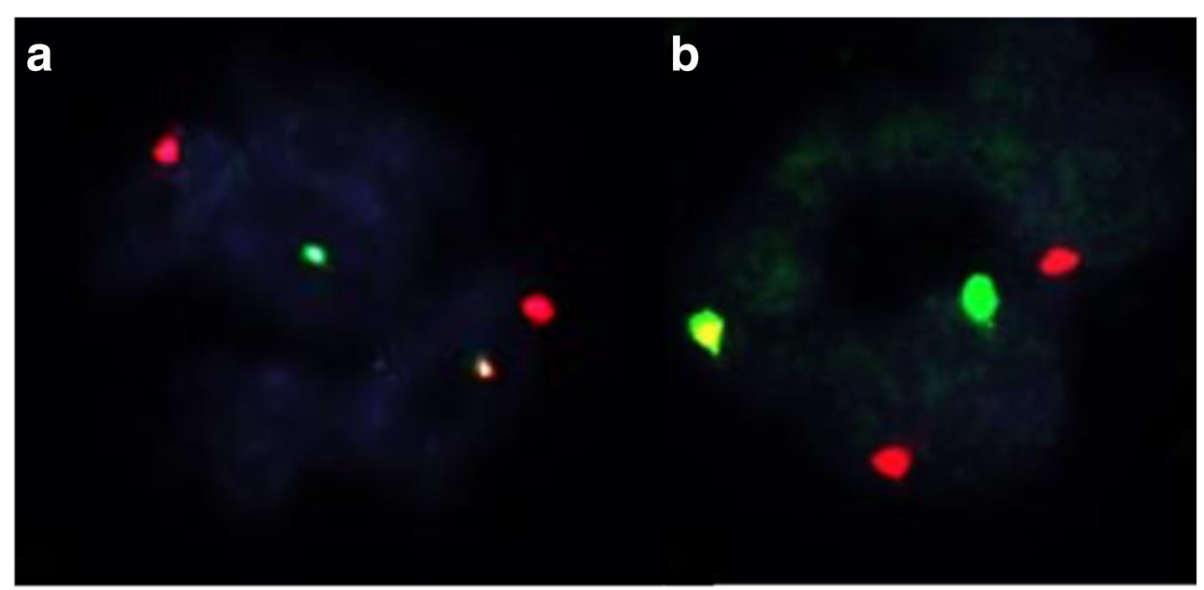

Fig. 5 Fluorescence in-situ hybridization studies demonstrating $t(14 ; 16)(q 32 ; q 23)$ in both mediastinal lymph node (a) and gingival biopsy (b). The abnormal signaling patterns are 2R1G1F (a) and 2R1G1F (b) by dual color, dual fusion probes 
cells to commit to the granulocyte-monocyte lineage [34]. Xie et al. showed overexpression of C/EBP $\alpha$ and $C /$ EBP $\beta$ converted mature murine $B$ cells into macrophages by suppressing PAX-5 expression [29]. Furthermore, studies using $\mathrm{C} / \mathrm{EBP} \alpha$ transgenic mice suggest that $\mathrm{B}$ cells are directly converted to other lineages through a biphenotypic intermediate cells rather than a two-step process of dedifferentiation and redifferentiation [34]. In support of a mechanism involving direct transdifferentiation, Feldman et al. showed loss of PAX-5 expression and up regulation of PU.1 and CEBP $\beta$ in eight cases of histiocytic-dendritic cell sarcomas derived from antecedent follicular lymphoma [12]. Since we do not know the expression pattern of PU.1, C/EBP $\alpha$ or C/ $E B P \beta$ in these soft tissue tumors, their role in lineage transformation is unclear. However, PAX-5 was not expressed in the original PCM, therefore down regulation of PAX-5 cannot explain the development of monocytic-macrophage lineage. MUM-1, a transcription factor required for plasma cell differentiation [35], was expressed in the original plasma cell tumor but was not detected in the myeloid sarcomas (Figs. 1 and 3). Whether down-regulation of MUM-1 contributes to monocyte-macrophage transformation in plasma cell myeloma is unknown.

Limited data exist regarding the molecular genetics of transformed myeloid sarcoma; however several reports evaluating secondary HS suggest molecular complexity and heterogeneity. Similar to our case showing loss of CDKN2A/B, loss of CDKN2A has been reported in HS subsequent to B-lymphoblastic leukemia $[15,36]$. BRAF V600E mutation has been reported in de novo HS [37] and HS following splenic marginal zone lymphoma [13] and hairy cell leukemia [38]. NGS analysis of the myeloid sarcoma in this case showed a clonal, non V600E activating mutation in BRAF. The BRAF mutation (G469A) is distinct from other variants identified in de novo HS, including BRAF F595 L, BRAF (G466R), BRAF (G464 V) and BRAF (N581S); however, as in this case, these BRAF variants are not mutually exclusive with activating RAS mutations $[39,40]$.

Like other cases of secondary HS [23], a clonal relationship between the primary PCM and secondary tumor in current case was confirmed by FISH and NGS analyses showing IGH-MAF gene rearrangement, and similar genomic alterations in KRAS, BRAF and MAK3K6. IGH-MAF translocation is present in 3-6\% of PCM cases [41] and this molecular subtype often shows concurrent activating mutations in RAS-RAF and NF-kB signaling pathways [42]. In human cell lines, c-MAF promotes monocyte-macrophage differentiation through downreguation of CEBP $\alpha$ [43], suggesting a possible role of $\mathrm{c}-\mathrm{MAF}$ in PCM phenotypic transformation.
In addition to shared clonal abnormalities, additional aberrancies were detected in the sarcoma tumor cells, including deletion of a subclone of BRAF (G466A), loss of TRAF3 R505 and new clonal mutations in NF1 and TNFAIP3 (Table 1). TRAF3 is a critical determinant of B cell survival and loss of function mutations in TRAF3 and TNFAIP3 are associated with B cell malignancies and PCM [44, 45]. NF1 mutation, a negative regulator of RAS signaling, has been reported in rare cases of plasma cell myeloma [4] and approximately $4 \%$ of acute myeloid leukemia [46], but not reported in HS.

It is uncertain whether the molecular switch from PCM to a myeloid lineage tumor involves direct transdifferentiation via transcription factor dysregulation as suggested for B cell lymphomas, or whether the myeloid lineage tumors arose from a distinct, neoplastic clone that expanded following chemotherapy [12, 15-18]. Regardless of the mechanism, NGS findings suggest a clonal relationship with clonal evolution and a possible role of NF1, TNFAIP3 and TRAF3 in myeloid transformation of plasma cell myeloma.

\section{Conclusion}

To our knowledge, this is the first reported case of PCM transformation to a secondary tumor with monocytemacrophage lineage. As in other reports, the response to chemotherapy and prognosis is poor with patients dying from progressive disease $[18,19,23,25,26]$. This study highlights the importance of molecular analysis to establish a clonal relationship in metachronous or synchronous tumors, as addressed by other reports [47, 48]. The findings of an additional mutation in RAS-BRAF signaling (NF1 mutation) and NF-kB activation (TNFAIP3) suggests multiple mechanisms contribute to lineage transformation.

\section{Abbreviations}

FISH: Fluorescence in situ hybridization; HS: Histiocytic sarcoma; MPO: Myeloperoxidase; MS: Myeloid sarcoma; NGS: Next generation sequencing; PCM: Plasma cell myeloma

\section{Acknowledgements \\ We thank the University of Arkansas for Medical Sciences Department of Pathology for providing funds to perform IGH gene rearrangement studies and the molecular laboratory staff who performed this assay (Stacie Delaune and Molly Robbins).}

\section{Funding}

Not applicable.

\section{Availability of data and materials}

All data generated or analyzed during this study are included in this published article.

\section{Authors' contributions}

JG, GRP, FVR and YY collected case information. JG, GRP and YY wrote the manuscript. JG, GRP, FVR and YY edited the manuscript. All authors have read and approve the final manuscript. 


\section{Ethics approval and consent to participate}

Not applicable.

\section{Consent for publication}

Written informed consent for publication of their clinical details and/or clinical images was obtained from the patient. A copy of the consent form is available for review by the Editor of this journal.

\section{Competing interests}

The authors declare that they have no competing interests.

\section{Publisher's Note}

Springer Nature remains neutral with regard to jurisdictional claims in published maps and institutional affiliations.

\section{Author details}

'Department of Pathology, University of Arkansas for Medical Sciences, Little Rock, AR 72205-7199, USA. ${ }^{2}$ Myeloma Institute, University of Arkansas for Medical Sciences, Little Rock, AR, USA.

\section{Received: 30 October 2017 Accepted: 12 February 2018}

\section{Published online: 20 February 2018}

\section{References}

1. Rawstron AC, Orfao A, Beksac M, Bezdickova L, Brooimans RA, Bumbea $H$, Dalva K, Fuhler G, Gratama J, Hose D, et al. Report of the European myeloma network on multiparametric flow cytometry in multiple myeloma and related disorders. Haematologica. 2008;93(3):431-8.

2. Zhan F, Huang Y, Colla S, Stewart JP, Hanamura I, Gupta S, Epstein J, Yaccoby S, Sawyer J, Burington B, et al. The molecular classification of multiple myeloma. Blood. 2006;108(6):2020-8.

3. Bolli N, Avet-Loiseau H, Wedge DC, Van Loo P, Alexandrov LB, Martincorena I, Dawson KJ, lorio F, Nik-Zainal S, Bignell GR, et al. Heterogeneity of genomic evolution and mutational profiles in multiple myeloma. Nat Commun. 2014;5:2997.

4. Lohr JG, Stojanov P, Carter SL, Cruz-Gordillo P, Lawrence MS, Auclair D, Sougnez C, Knoechel B, Gould J, Saksena G, et al. Widespread genetic heterogeneity in multiple myeloma: implications for targeted therapy. Cancer Cell. 2014;25(1):91-101.

5. Lee CK, Ma ES, Shek TW, Lam CC, Au WY, Wan TS, Chan LC. Plasmablastic transformation of multiple myeloma. Hum Pathol. 2003;34(7):710-4.

6. Fernandez de Larrea C, Jimenez R, Rosinol L, Gine E, Tovar N, Cibeira MT, Fernandez-Aviles F, Martinez C, Rovira M, Blade J. Pattern of relapse and progression after autologous SCT as upfront treatment for multiple myeloma. Bone Marrow Transplant. 2014;49(2):223-7.

7. Ambrosio MR, De Falco G, Gozzetti A, Rocca BJ, Amato T, Mourmouras V, Gazaneo S, Mundo L, Candi V, Piccaluga PP, et al. Plasmablastic transformation of a pre-existing plasmacytoma: a possible role for reactivation of Epstein Barr virus infection. Haematologica. 2014;99(11):e235-7.

8. Epstein J, Xiao HQ, He XY. Markers of multiple hematopoietic-cell lineages in multiple myeloma. N Engl J Med. 1990;322(10):664-8.

9. Mailankody S, Pfeiffer RM, Kristinsson SY, Korde N, Bjorkholm M, Goldin LR, Turesson I, Landgren O. Risk of acute myeloid leukemia and myelodysplastic syndromes after multiple myeloma and its precursor disease (MGUS). Blood. 2011;118(15):4086-92.

10. Singh ZN, Jethava Y, Post GR, Alapat D, Sawyer J, Waheed S, Nair B, Usmani SZ, Bailey C, Petty N, et al. Fulminant onset of acute leukemia from normal hematopoiesis within 3 months of follow up for multiple myeloma treated with total therapy protocols. Clin Case Rep. 2015;3(3):183-92.

11. Nguyen TT, Schwartz EJ, West RB, Warnke RA, Arber DA, Natkunam Y. Expression of CD163 (hemoglobin scavenger receptor) in normal tissues, lymphomas, carcinomas, and sarcomas is largely restricted to the monocyte/macrophage lineage. Am J Surg Pathol. 2005;29(5):617-24.

12. Feldman AL, Arber DA, Pittaluga S, Martinez A, Burke JS, Raffeld M, Camos M, Warnke R, Jaffe ES. Clonally related follicular lymphomas and histiocytic/ dendritic cell sarcomas: evidence for transdifferentiation of the follicular lymphoma clone. Blood. 2008;111(12):5433-9.

13. West DS, Dogan A, Quint PS, Tricker-Klar ML, Porcher JC, Ketterling RP, Law ME, McPhail ED, Viswanatha DS, Kurtin PJ, et al. Clonally related follicular lymphomas and Langerhans cell neoplasms: expanding the spectrum of transdifferentiation. Am J Surg Pathol. 2013;37(7):978-86.
14. Nichols CR, Roth BJ, Heerema N, Griep J, Tricot G. Hematologic neoplasia associated with primary mediastinal germ-cell tumors. N Engl J Med. 1990; 322(20):1425-9.

15. Alten J, Klapper W, Leuschner I, Eckert C, Beier R, Vallo E, Krause M, Claviez A, Vieth S, Bleckmann K, et al. Secondary histiocytic sarcoma may cause apparent persistence or recurrence of minimal residual disease in childhood acute lymphoblastic leukemia. Pediatr Blood Cancer. 2015;62(9):1656-60.

16. Feldman AL, Minniti C, Santi M, Downing JR, Raffeld M, Jaffe ES. Histiocytic sarcoma after acute lymphoblastic leukaemia: a common clonal origin. Lancet Oncol. 2004;5(4):248-50.

17. Fraser CR, Wang W, Gomez M, Zhang T, Mathew S, Furman RR, Knowles DM, Orazi A, Tam W. Transformation of chronic lymphocytic leukemia/small lymphocytic lymphoma to interdigitating dendritic cell sarcoma: evidence for transdifferentiation of the lymphoma clone. Am J Clin Pathol. 2009; 132(6):928-39.

18. Stoecker MM, Wang E. Histiocytic/dendritic cell transformation of B-cell neoplasms: pathologic evidence of lineage conversion in differentiated hematolymphoid malignancies. Arch Pathol Lab Med. 2013;137(6):865-70.

19. Thakral B, Khoury JD. Histiocytic sarcoma: secondary neoplasm or "transdifferentiation" in the setting of B-acute lymphoblastic leukemia. Blood. 2016;128(20):2475.

20. Vaughn JL, Freitag CE, Hemminger JA, Jones JA. BRAF V600E expression in histiocytic sarcoma associated with splenic marginal zone lymphoma: a case report. J Med Case Rep. 2017;11(1):92.

21. Ambrosio MR, De Falco G, Rocca BJ, Barone A, Amato T, Bellan C, Lazzi S, Leoncini L. Langerhans cell sarcoma following marginal zone lymphoma: expanding the knowledge on mature B cell plasticity. Virchows Arch. 2015; 467(4):471-80

22. Buser L, Bihl M, Rufle A, Mickys U, Tavoriene I, Griskevicius L, Tzankov A. Unique composite hematolymphoid tumor consisting of a pro- $T$ lymphoblastic lymphoma and an indeterminate dendritic cell tumor: evidence for divergent common progenitor cell differentiation. Pathobiology. 2014;81(4):199-205.

23. Ansari J, Naqash AR, Munker R, El-Osta H, Master S, Cotelingam JD, Griffiths E, Greer AH, Yin H, Peddi $\mathrm{P}$, et al. Histiocytic sarcoma as a secondary malignancy: pathobiology, diagnosis, and treatment. Eur J Haematol. 2016; 97(1):9-16.

24. Zhao J, Niu X, Wang Z, Lu H, Lin X, Lu Q. Histiocytic sarcoma combined with acute monocytic leukemia: a case report. Diagn Pathol. 2015;10:110.

25. Takahashi E, Nakamura S. Histiocytic sarcoma : an updated literature review based on the 2008 WHO classification. J Clin Exp Hematop. 2013;53(1):1-8.

26. Grogan TM, et al. Histiocytic sarcoma. In: SHCE S, Harris NL, Jaffe ES, Pileri SA, Stein H, Thiele J, Vardiman JW, editors. WHO classification of Tumours of Haematopoietic and lymphoid tissues. Lyon: International Agency for Research on Cancer (IARC); 2008. p. 356

27. Rocca BJ, Ambrosio MR, Gozzetti A, Bocchia M, Leoncini L, Lazzi S. Myeloid sarcoma and adenocarcinoma of the large bowel as collision tumors: a case report. Histol Histopathol. 2012;27(7):941-7.

28. Laslo P, Spooner CJ, Warmflash A, Lancki DW, Lee HJ, Sciammas R, Gantner BN, Dinner AR, Singh H. Multilineage transcriptional priming and determination of alternate hematopoietic cell fates. Cell. 2006;126(4):755-66.

29. Xie H, Ye M, Feng $R$, Graf T. Stepwise reprogramming of $B$ cells into macrophages. Cell. 2004;117(5):663-76.

30. Nakajima $\mathrm{H}$. Role of transcription factors in differentiation and reprogramming of hematopoietic cells. Keio J Med. 2011;60(2):47-55.

31. Mikkola I, Heavey B, Horcher M, Busslinger M. Reversion of B cell commitment upon loss of Pax5 expression. Science. 2002;297(5578):110-3.

32. Nutt SL, Heavey B, Rolink AG, Busslinger M. Commitment to the B-lymphoid lineage depends on the transcription factor Pax5. Nature. 1999;401(6753): 556-62.

33. Schebesta M, Heavey B, Busslinger M. Transcriptional control of B-cell development. Curr Opin Immunol. 2002;14(2):216-23.

34. Fukuchi $Y$, Shibata $F$, Ito $M$, Goto-Koshino $Y$, Sotomaru $Y$, Ito $M$, Kitamura $T$, Nakajima H. Comprehensive analysis of myeloid lineage conversion using mice expressing an inducible form of C/EBP alpha. EMBO J. 2006;25(14): 3398-410.

35. Shinnakasu R, Kurosaki T. Regulation of memory B and plasma cell differentiation. Curr Opin Immunol. 2017;45:126-31.

36. Kumar R, Khan SP, Joshi DD, Shaw GR, Ketterling RP, Feldman AL. Pediatric histiocytic sarcoma clonally related to precursor B-cell acute lymphoblastic 
leukemia with homozygous deletion of CDKN2A encoding p16INK4A. Pediatr Blood Cancer. 2011;56(2):307-10.

37. Go H, Jeon YK, Huh J, Choi SJ, Choi YD, Cha HJ, Kim HJ, Park G, Min S, Kim JE. Frequent detection of BRAF(V600E) mutations in histiocytic and dendritic cell neoplasms. Histopathology. 2014;65(2):261-72.

38. Michonneau D, Kaltenbach S, Derrieux C, Trinquand A, Brouzes C, Gibault L, North MO, Delarue R, Varet B, Emile JF, et al. BRAF(V600E) mutation in a histiocytic sarcoma arising from hairy cell leukemia. J Clin Oncol. 2014; 32(35):e117-21.

39. Liu Q, Tomaszewicz K, Hutchinson L, Hornick JL, Woda B, Yu H. Somatic mutations in histiocytic sarcoma identified by next generation sequencing. Virchows Arch. 2016;469(2):233-41.

40. Kordes M, Roring M, Heining C, Braun S, Hutter B, Richter D, Georg C, Scholl C, Groschel S, Roth W, et al. Cooperation of BRAF(F595L) and mutant HRAS in histiocytic sarcoma provides new insights into oncogenic BRAF signaling. Leukemia. 2016;30(4):937-46.

41. Avet-Loiseau H, Malard F, Campion L, Magrangeas F, Sebban C, Lioure B, Decaux O, Lamy T, Legros L, Fuzibet JG, et al. Translocation $\mathrm{t}(14 ; 16)$ and multiple myeloma: is it really an independent prognostic factor? Blood. 2011;117(6):2009-11.

42. Stein CK, Pawlyn C, Chavan S, Rasche L, Weinhold N, Corken A, Buros A, Sonneveld P, Jackson GH, Landgren $\mathrm{O}$, et al. The varied distribution and impact of RAS codon and other key DNA alterations across the translocation cyclin D subgroups in multiple myeloma. Oncotarget. 2017: 8(17):27854-67.

43. Hegde SP, Zhao J, Ashmun RA, Shapiro LH. C-Maf induces monocytic differentiation and apoptosis in bipotent myeloid progenitors. Blood. 1999; 94(5):1578-89.

44. Moore CR, Liu Y, Shao C, Covey LR, Morse HC 3rd, Xie P. Specific deletion of TRAF3 in B lymphocytes leads to B-lymphoma development in mice. Leukemia. 2012;26(5):1122-7.

45. Troppan K, Hofer S, Wenzl K, Lassnig M, Pursche B, Steinbauer E, Wiltgen M, Zulus B, Renner W, Beham-Schmid C, et al. Frequent down regulation of the tumor suppressor gene a20 in multiple myeloma. PLoS One. 2015;10(4):e0123922.

46. Boudry-Labis E, Roche-Lestienne C, Nibourel O, Boissel N, Terre C, Perot C, Eclache V, Gachard N, Tigaud I, Plessis G, et al. Neurofibromatosis-1 gene deletions and mutations in de novo adult acute myeloid leukemia. Am J Hematol. 2013;88(4):306-11.

47. Amato T, Abate F, Piccaluga P, lacono M, Fallerini C, Renieri A, De Falco G, Ambrosio MR, Mourmouras V, Ogwang M, et al. Clonality analysis of immunoglobulin gene rearrangement by next-generation sequencing in endemic Burkitt lymphoma suggests antigen drive activation of $B C R$ as opposed to sporadic Burkitt lymphoma. Am J Clin Pathol. 2016;145(1): 116-27.

48. Ambrosio MR, Rocca BJ, Ginori A, Mourmouras V, Amato T, Vindigni C, Lazzi S, Leoncini L. A look into the evolution of Epstein-Barr virus-induced lymphoproliferative disorders: a case study. Am J Clin Pathol. 2015;144(5): $817-22$

\section{Submit your next manuscript to BioMed Central and we will help you at every step:}

- We accept pre-submission inquiries

- Our selector tool helps you to find the most relevant journal

- We provide round the clock customer support

- Convenient online submission

- Thorough peer review

- Inclusion in PubMed and all major indexing services

- Maximum visibility for your research

Submit your manuscript at www.biomedcentral.com/submit

) Biomed Central 